\title{
PENGGUNAAN INTERNET TERHADAP PENINGKATAN PARTISIPASI POLITIK DAN KEHIDUPAN DEMOKRASI
}

\author{
Reny Yuliati \\ Ilmu Komunikasi, Universitas Brawijaya \\ Alamat surel: renyyuliati@yahoo.com
}

\begin{abstract}
Internet is a medium that become increasingly in demand by society from different circle. With the Internet as new media brings some changes on how people can voice their aspirations. The purpose of this article is to look at the advantages of new media in enhancing political participation and democracy compared with traditional media. With the new media, we have a great hope in democracy in Indonesia as long as government and citizens use it wisely.
\end{abstract}

Keywords: new media, democracy, political participation

\begin{abstract}
Abstrak
Internet merupakan sebuah media yang semakin hari semakin diminati oleh masyarakat dari berbagai kalangan. Dengan adanya internet sebagai media baru memunculkan beberapa perubahan terhadap bagaimana seseorang dapat menyuarakan aspirasinya. Tujuan dari penulisan artikel ini adalah untuk melihat kelebihan-kelebihan media baru dalam meningkatkan partisipasi politik dan demokasi dibandingkan dengan media tradisional. Dengan adanya media baru, kita mempunyai harapan yang besar dalam demokrasi di Indonesia selama pemerintah beserta masyarakat menggunakannya dengan bijak.

Kata kunci: media baru, demokrasi, partisipasi politik
\end{abstract}

\section{PENDAHULUAN}

Media baru atau yang sering disebut sebagai new media merupakan media yang berbeda dengan media tradisional. Media baru merupakan media yang menggunakan perantara komputer untuk mengabungkan komunikasi antara manusia satu dengan lainnya. Penggunaan komputer ini diakibatkan karena berkembangnya teknologi komunikasi yang tidak pernah berhenti selama manusia dapat berfikir. Internet sebagai media baru, menggabungkan antara radio, film dan televisi sehingga disebut juga dengan konvergensi media. Menurut McQuail, Internet melampaui batas-batas model media cetak dan siaran yang memungkinkan manyto-many conversation; resepsi, alterasi dan redistribusi objek kultural secara simultan; mendislokasi tindak komunikatif dari batasbatas bangsa; memberikan kontak global yang seketika itu juga dan memasukkan sesuatu yang modern kedalam suatu perangkat mesin yang dirangkaikan ${ }^{1}$.

Beberapa pakar komunikasi meyakini bahwa setiap tahapan atau temuan teknologi komunikasi yang baru akan berdampak terjadinya perubahan sosial masyarakat. Marshall McLuhan ${ }^{2}$ menjelaskan bahwa penemuan mesin cetak yang diikuti oleh media elektronik, benarbenar mengubah sejarah peradaban umat manusia secara revolusioner. Pemanfaatan teknologi komunikasi berbasis teknologi elektronik membuat dunia semakin terasa sempit yang akhirnya mendapat sebutan sebuah desa dunia (global village), terutama semakin kaburnya batas-batas negara, sehingga kita bisa mengatasi kendala ruang dan waktu.

Selain merubah tatanan kehidupan manusia sehari-hari, media baru ternyata

\footnotetext{
${ }^{1}$ McQuail, Dennis. Mass Communication Theory Fifth Edition (London: Sage Publications Ltd., 2005), hlm. 138

${ }^{2}$ McLuhan, M. 1964. Understanding Media : The Extensions of Man. New York : McGraw Hill
}

Jurnal Bricolage Vol. 2 No. 2 
juga mendukung terjadinya perubahan gelombang demokrasi di berbagai negara, tak terkecuali di Indonesia. Hal ini sesuai dengan yang dinyatakan Schudson (dalam Firmansyah $^{3}$ ) bahwa internet sebagai media komunikasi dan pertukaran informasi, berpeluang merevolusi sistem, struktur dan proses demokrasi yang selama ini kita kenal. Ini berarti bahwa internet bukan hanya dipandang sebagai sebuah medium komunikasi biasa, tetapi lebih jauh lagi dan berdampak luar biasa terhadap kehidupan politik suatu negara.

\section{Media Baru Dalam Memproduksi Demokrasi}

Media massa tradisional yakni media cetak dan media siar (broadcasting) secara meluas dipandang sebagai alat yang berguna untuk menyebarkan politik demokrasi. Kelebihan dari media tradisional tersebut terdapat dari mengalirnya berbagai informasi mengenai peristiwa publik, politik dan pemerintah kepada seluruh warga negara. Namun kekurangan media massa tradisional adalah adanya dominasi saluran sehingga hanya memuat sedikitnya suara dan komersialisme pasar media. Hal ini seakan membuat media massa tradisional sia-sia saja dalam mewadahi komunikasi demokratis. Bentuk komunikasi massa tradisional juga membatasi akses dan mencegah partisipasi yang aktif dari pemirsanya.

Munculnya media baru disambut secara meluas. Media baru dipandang sebagai suatu cara potensial untuk membebaskan dari tekanan politik "topdown". Politik top-down secara ketat mengorganisasi partai politiknya, membuat kebijakan secara sepihak dan mengerahkan dukungan dengan negosiasi yang minimal tanpa masukan atau input dari akar rumput. Sedangkan, media baru sanggup menyuguhkan informasi dan ide politik dengan akses yang yang tak terbatas untuk semua suara, banyaknya umpan balik

3 Firmansyah. Marketing Politik - Antara Pemahaman dan Realitas. (Jakarta : Yayasan Obor Indonesia, 2008) (feedback) dan negosiasi antara pimpinan dan pengikutnya.

Bentivegna $^{4}$ telah merangkum keuntungan manfaat potensial internet terhadap politik dalam enam atribut utama,yaitu 1) interaktif, tidak satu arah; 2) kehadiran bersamaan (co-presence) komunikasi vertikal maupun horisontal, sehingga menimbulkan kesetaraan; 3) disintermediasi, peran media dan wartawan sebagai mediator tereduksi, masyarakat dapat langsung berkomunikasi dengan politisi mereka; 4) biaya yang murah antara pengirim dan penerima; 5) kecepatan yang tidak dapat ditandingi media konvensional; 6) tidak adanya batasan.

Sedangkan jika ditinjau dari perspektif utopian ${ }^{5}$ manfaat yang didapatkan dari penggunaan internet dalam partisipasi politik antara lain : 1) Menanggulangi keterpaksaan karena adanya batasan komunitas, 2) Komunitas dunia maya bisa lebih bersemangat dan supportive, 3) Lebih mudah menciptakan shared information dan suara komunitas, 4) Komunitas online bisa mendorong suatu aktivitas tanpa batasan wilayah, 5) Komunitas online bisa menjadi pelengkap hubungan offline, 6) Membantu mengembangkan dialog.

\footnotetext{
${ }^{4}$ McQuail, Dennis. Mass Communication Theory Fifth Edition (London: Sage Publications Ltd., 2005)

5 Perspektif Utopian adalah prediksi masa depan yang mempercayai bahwa penggunaan internet dalam demokrasi dan dalam partisipasi politik lebih banyak ke sisi menguntungkan, sebaliknya prediksi yang lebih banyak ke sisi negatif atau merugikan adalah perspektif dystopian, yang banyak dianut oleh negara otoriter. Perspektif dystopian menganggap bahwa partisipasi politik melalui internet hanya akan mempersempit jangkauan partisipan karena pengguna internet biasanya terbatas pada kaum muda, selain itu juga menimbulkan keterbatasan diskursus karena voting elektronik tidak melibatkan debat/diskusi dan pemilih cenderung pasif. Ibid . hlm 103-108. Disini penulis cenderung mendukung utopian sebagai perspektif yang sesuai dengan sistem politik di Indonesia yang bukan otoriter.
} 
Selain kelebihan media baru dalam kaitannya dengan politik, ternyata internet juga memiliki keterbatasan yang mencegah transformasi demokratis. Dalam pandangan Bentiviegna (2002), kesenjangan individu yang aktif dalam politik dengan sebagian besar yang tidak aktif justru meluas, karena media baru cenderung digunakan oleh minoritas atau sebagian kecil orang yang tertarik dan terlibat secara politis. Keterbatasan lainnya adalah karena melimpah ruahnya informasi yang ada di internet, bisa mengaburkan beberapa informasi yang penting dan terlalu banyaknya suara atau pendapat juga merupakan penghalang bagi pembahasan yang serius.

Namun yang paling penting disini bahwa media baru menjanjikan forum baru untuk perkembangan kelompok kepentingan dan berbagai bentuk opini. Coleman (1999) menyatakan peran dari media baru adalah dalam layanan subversif (bersifat menggulingkan pemerintahan) yang muncul dari ekspresi kebebasan dibawah kontrol authoritarian. Layanan subversif internet bisa dilihat dari sejarah masuknya internet pertama kali di Indonesia yang pada akhirnya merubah demokrasi besar-besaran di negara ini.

Pada saat itu, Internet masuk di kepulauan Indonesia pada tahun 1990an ${ }^{6}$. Muncul warung-warung internet (warnet) dimana semua orang bisa mengakses teknologi baru tersebut. Karena karateristik internet yang sangat sulit untuk dikontrol maupun disensor, siapapun tidak bisa mengontrol gambar ataupun pesan dari email ataupun milis yang dikirimkan dari seseorang ke orang lainnya. Hal inilah yang akhirnya dimanfaatkan oleh para pelajar, NGO (Non Government Organization) dan para kelas menengah urban untuk membangun suatu oposisi terhadap pemerintahan Soeharto pada saat itu. Mereka bergerilya melalui internet dengan menggunakan forum-forum seperti milis,

\footnotetext{
${ }^{6}$ Hill, David T and Kreshna Sen. The Internet in Indonesia's New Democracy (New York: Routledge, 2005), hlm 1
}

saling berbagi tentang protes maupun demonstrasi yang ada melalui email, menyebarluaskan dugaan dan bukti korupsi Presiden Soeharto di berbagai news group. Dan pada akhirnya memicu aksi unjuk rasa besar-besaran yang meruntuhkan era otoriter yang dipimpin Soeharto ${ }^{7}$. Dari sejarah itulah, yang pada akhirnya melahirkan konsep demokrasi melalu media baru di Indonesia yang terus berkembang sampai sekarang ini.

\section{Peran Media Baru dalam Politik}

Menurut Dahlberg ${ }^{8}$ setidaknya ada tiga peran media baru dalam politik, yang pertama yaitu cyber-libertarianism, sebuah pendekatan politik berdasarkan model pasar konsumen yang berupa survey, televoting, dan pemungutan suara. Untuk pemungutan suara atau voting, hampir setiap portal berita di Indonesia, telah menyusun pertanyaanpertanyaan mengenai isu-isu pemerintahan dan publik, seperti pada kpu.go.id dan detiknews.com.

$$
\text { Yang kedua adalah }
$$

communitarian, kehadiran new media diharapkan dapat memperluas partisipasi politik di tingkat akar rumput dan memperkuat komunitas politik lokal. Pendekatan ini berakar pada kenyataan bahwa internet menciptakan persamaan derajat dan asal muasal manusia. Semua orang bisa memberikan kontribusi dalam diskusi online. Milis, situs komunitas, dan forum terbuka yang biasa digunakan oleh para pengguna internet untuk mengungkap pendapat dan opini. E-government, forum lepas, penulis lepas, dan berbagai milis lainnya adalah terobosan yang dimanfaatkan untuk menampung berbagai apirasi pendapat, opini, ide, saran, maupun kritik.

Penggunaan hak bersuara dan beropini dalam media baru ini sekaligus

\footnotetext{
7 Ibid, hlm 141

${ }^{8}$ Dahlberg, L. 2001. Democracy via Cyberspace: Mapping the rhetorics and practices of three prominent camps. http://is.muni.cz/el/1423/jaro2012/ZURs203/u $\mathrm{m} /$ Literatura/Dahlberg_-

_Democracy_via_cyberspace.pdf
} 
menyangkal prinsip teori spiral of silence yang dikemukakan oleh Elisabeth NoelleNeumann. Menurut Elisabeth NoelleNeumann", "pengamatan yang dibuat dalam satu konteks (media massa) menyebar kepada yang lain dan mendorong orang untuk menyuarakan pandangan mereka atau menelannya dan diam, hingga, dalam sebuah proses yang spiral, satu pandangan dianggap mendominasi ranah publik sementara yang lain hilang dari kesadaran publik dan para pendukungnya tidak bersuara lagi. Hal inilah yang disebut spiral of silence." Dengan perkataan lain, karena orang takut pada keterasingan atau pemisahan dari sekeliling mereka, mereka cenderung menjaga sikap ketika merasa pada kalangan minoritas. Namun apa yang ditunjukkan oleh teori spiral of silence ini, justru berbeda dengan apa yang ada dalam penggunaan media baru. Kebebasan dalam menyampaikan suara melalui media internet bahkan tidak memandang siapa identitas pengirim informasi, tetapi lebih kepada isi pesan yang disampaikan. Begitu juga dengan munculnya forum-forum kelompok minoritas di Internet yang bisa bebas berpendapat tanpa adanya rasa takut diasingkan oleh kaum mayoritas. Pada media internet, justru orang yang minoritas ini bisa menggalang suara dengan orang lain yang mempunyai pandangan yang sama dengan cara yang sangat mudah. Dalam waktu singkat saja suatu forum kelompok bisa terbentuk dengan banyak anggota. Kelompok kaum minoritas inilah yang sebenarnya juga harus dijangkau oleh para politisi dan pemerintah jika demokrasi melalui internet benar-benar ingin tercapai dan merata tanpa memandang bulu warga negaranya.

Yang ketiga yaitu deliberative democracy (demokrasi yang membebaskan) dimana media baru itu memungkinkan interaksi dan pertukaran gagasan di ranah publik. Adanya interaksi diantara pengguna internet, menyebabkan perbedaan dalam

\footnotetext{
9 Baran, Stanley J. dan Dennis K. Davis. Teori Komunikasi Massa : Dasar, Pergolakan dan Masa Depan (Jakarta : Salemba Humanika, 2010), hlm 352
}

pengaturan agenda publik. Seperti yang diketahui di dalam media massa konvensional, berlaku adanya teori agenda setting, dimana prinsip dari teori agenda setting adalah bahwa kita akan cenderung menilai sesuatu itu penting sebagaimana media massa menganggap hal tersebut penting. Jika media massa menganggap suatu isu itu penting maka kita juga akan menganggapnya penting, begitu pula sebaliknya. Namun, meledaknya jumlah informasi melalui internet, adanya interaksi dan pertukaran gagasan diantara para pengguna internet memperlemah asumsi ini, dan para pengguna internet bisa menyeleksi informasi mana yang dianggap penting bagi mereka sesuai dengan kepentingan masingmasing.

Media baru, bagaimanapun memaksa perubahan pada beberapa prinsip dari teori agenda setting. Contohnya, meningkatnya interaksi dan konektifitas sosial menghasilkan suatu aplikasi web yang berisi tulisan-tulisan yang dipostingkan dalam web umum dan disebut sebagai blog. Berita dan informasi di dalam blog bisa ditulis oleh siapapun, sehingga disebut juga dengan citizen journalism. Hubungan antara blog dengan media mainstream (cetak dan siar) sangat kompleks. Bisa jadi apa yang ditulis di blog membentuk sebuah agenda yang dipengaruhi media mainstream, atau bahkan bisa juga suatu blog tidak berisikan atau tidak sama dengan agenda berita mainstream. Contohnya, blogger berhasil menyorot pandangan seorang senator Amerika Serikat yang bernama Lott, dimana ia sepakat tentang segregasi rasial, padahal saat itu media mainstream lainnya tidak menyoroti pandangan Lott. Selain itu juga ada kasus seorang blogger yang bernama Iwan Piliang, yang berhasil mengungkap kasus pembunuhan David Hartanto Widjaya, seorang mahasiswa Indonesia yang tewas di Singapura.

Hingga saat ini, jumlah penggunaan blogger di Indonesia diperkirakan menembus 1 juta pada tahun $2010^{10}$, dan jumlah itu merupakan peningkatan yang

${ }^{10}$ kilasberita.com 
terjadi signifikan dari tahun-tahun sebelumnya. Siapapun bisa membuat dan menggunakan blog dan ini merupakan pertanda demokrasi yang baik karena seperti yang disebutkan oleh Davis dan Baran, bahwa blogger dapat mengawasi media dan politisi dengan komentar mereka ${ }^{11}$. Di sini orang tanpa hambatan dan tekanan bisa mengeluarkan uneg-uneg, membantu pemerintah atau bahkan mengkritik, misalnya, dalam menjalankan fungsi-fungsi kenegaraan. Hal tersebut juga diperkuat McChesney $^{12}$, yang menyatakan bahwa internet merupakan pelopor demokrasi yang potensial seperti "watchdog" atau pilar ke empat suatu negara (setelah eksekutif, legislatif dan yudikatif). Sehingga peran blog sangat signifikan jika ingin mendirikan demokrasi yang utuh.

\section{Masa Depan Penggunaan Internet Sebagai Alat Demokrasi di Indonesia}

Penggunaan internet untuk masyarakat luas di seluruh Indonesia, didukung oleh pemerintah dengan membuat program Internet masuk desa. Di tahun 2010, ditargetkan program ini dapat tuntas dan konsep desa pintar segera teralisasi. Meskipun pada sampai tahun ini, di tahun 2017, masih terdapat area blank spot internet di daerah-daerah 3T (Terdepan, Terpencil dan Tertinggal). Dengan adanya dukungan pemerintah seperti ini, bisa jadi demokrasi di Indonesia semakin meningkat, masyarakat luas tidak buta akan informasi dan politik. Hal ini juga sejalan dengan hasil studi yang dilakukan UCLA (University of California Los Angeles) pada tahun $2000^{13}$, bahwa $45,6 \%$ dari pengguna internet (versus $28,1 \%$ bukan pengguna) merasa bahwa internet

\footnotetext{
${ }^{11}$ Baran, Stanley J. dan Dennis K. Davis. Teori Komunikasi Massa : Dasar, Pergolakan dan Masa Depan (Jakarta : Salemba Humanika, 2010), hlm 154

12 Dalam Allan,Stuart. The Routledge Companion to News and Journalism (London and New York : Routledge, 2010), hlm 10

13 Carey, 1988. Dalam Rice, Ronald E. et al. Social Consequences in Internet Use (MIT Press, 2002), hlm 107
}

memang membantu orang untuk lebih memahami politik.

Diharapkan pemilu di masa yang akan datang dapat dilakukan melalui internet tanpa harus mencoblos ke tempat pemilihan, seperti poling-poling kepuasan pemerintah yang sekarang ini tersebar di berbagai situs e-government maupun situs media. Proses dan hasil yang didapatkan juga akan lebih cepat dan akurat karena penghitungan berbasis komputer, sehingga lebih efektif dan efisien.

Penggunaan internet dalam ajang demokrasi juga harus lebih dioptimalkan dan sudah selayaknya pemerintah mulai berfikir akan aturan-aturan baru yang mendorong partisipasi politik melalui internet. Bukan malah membuat peraturan yang membatasi demokrasi di dalam media yang relatif baru ini. Pemerintah seharusnya lebih menilik peraturan mengenai kebebasan berpendapat di internet. Supaya tidak membatasi ruang publik di internet seperti kasus Prita yang berkeluh kesah lewat forum internet mengenai pelayanan rumah sakit, dan kasus yang menimpa blogger bernama Hariadhi, yang dilaporkan ke polisi karena diduga mencemarkan nama baik dan menyebarkan kabar bohong tentang Teh Botol Sosro produksi PT Sinar Sosro ${ }^{14}$.

\footnotetext{
${ }^{14} \mathrm{~B} \log$ Hariadi bisa dilihat pada alamat http://hariadhi.wordpress.com/?s=teh+botol+sosr o
}

Jurnal Bricolage Vol. 2 No. 2 


\section{DAFTAR PUSTAKA}

Allan,Stuart (edt). The Routledge Companion to News and Journalism. London and New York : Routledge. 2010

Baran, Stanley J. dan Dennis K. Davis. 2010. Teori Komunikasi Massa : Dasar, Pergolakan dan Masa Depan. Jakarta : Salemba Humanika.

Dahlberg, L. 2001. Democracy via Cyberspace: Mapping the rhetorics and practices of three prominent camps.

http://is.muni.cz/el/1423/jaro2012/

ZURs203/um/Literatura/Dahlberg

-_Democracy_via_cyberspace.pdf

Firmansyah. 2008. Marketing Politik Antara Pemahaman dan Realitas. Jakarta : Yayasan Obor Indonesia.

Hariadi. 11 Mei 2009. "Apakah Saya Menyesal?"

$<\mathrm{http}: / /$ hariadhi.wordpress.com/?s= teh+botol+sosro>. Diakses pada tanggal 24 Oktober 2010.
Hill, David T and Kreshna Sen. 2005. The Internet in Indonesia's New Democracy. New York. Routledge.

Kilasberita.com. 9 Januari 2009. "Tahun ini jumlah blogger Indonesia tembus 1 juta" $<$ http://www.kilasberita.com/k b-tech/internet/14286-tahun-inijumlah-blogger-indonesia-tembus1-juta>. Diakses pada tanggal 23 Oktober 2010.

McQuail, Dennis. 2005. Mass Communication Theory. Fifth Edition. London : Sage Publications Ltd.

McLuhan, M. 1964. Understanding Media : The Extensions of Man. New York : MCGraw Hill

Rice, Ronald E. et al. 2002. Social Consequences in Internet Use. New York :MIT Press.

Jurnal Bricolage Vol. 2 No. 2 